\title{
Étude des grès en Lorraine
}

\section{Alexandra Bayautet}

Édition électronique
URL : http://journals.openedition.org/adlfi/9019

ISSN : 2114-0502

Éditeur

Ministère de la culture

\section{Référence électronique}

Alexandra Bayautet, "Étude des grès en Lorraine », ADLFI. Archéologie de la France - Informations [En ligne], Lorraine, mis en ligne le 01 mars 2001, consulté le 03 mai 2019. URL : http:// journals.openedition.org/adlfi/9019

Ce document a été généré automatiquement le 3 mai 2019.

(c) Ministère de la Culture et de la Communication, CNRS 


\title{
Étude des grès en Lorraine
}

\author{
Alexandra Bayautet
}

Identifiant de l'opération archéologique : F1354200100061

Date de l'opération : 2001 (PT)

Depuis une trentaine d'années, l'archéologie médiévale s'est fortement développée. Cet essor se traduit par la multiplication d'opérations archéologiques, menées dans l'objectif de sauvegarder un patrimoine en danger. La Lorraine s'inscrit au cœur même de cette politique, comme peuvent en témoigner les nombreuses prospections et fouilles réalisées dans la région.

2 Le mobilier céramique est une des données archéologiques la plus souvent exhumée des sites lorrains. Véritable « document d'histoire ", la céramique médiévale a fait l'objet de plusieurs études. Contrairement à la poterie culinaire, certaines productions céramiques n'ont quasiment pas été étudiées en Lorraine. C'est le cas notamment de la poterie de grès. En quantité variable mais non négligeable, elle a été mise au jour au sein de nombreux sites lorrains. Cependant, aucune étude de ce mobilier n'a été entreprise. Pourtant, les chercheurs de certaines régions témoignent d'un vif intérêt pour la céramique en grès. À titre d'exemple, les travaux et les recherches se sont multipliés en Alsace, Normandie ou Beauvaisis (Nord-Picardie) qui furent des centres de production actifs.

3 La première partie de ce mémoire est consacrée à la bibliographie. Chaque ouvrage présenté est accompagné d'un descriptif résumant son contenu. Cette étude bibliographique est loin d'être exhaustive, néanmoins elle regroupe les ouvrages ayant permis d'éclairer nos zones d'ombres au sujet des grès.

4 Les sources écrites, archéologiques et iconographiques sont traitées respectivement au sein d'une deuxième partie.

5 Il apparaissait intéressant de réaliser un recensement exhaustif des objets dispersés dans divers dépôts lorrains (collections privées, musées, dépôts de fouille). La quantité de grès 
mise au jour varie en fonction du site ; la plus grande partie des grès ont été découverts en milieu urbain et castral.

Il faut souligner la position de la ville de Metz qui, par la quantité de grès exhumée, s'impose comme étant le centre le plus intéressant. De plus, le dépôt archéologique régional de Scy-Chazelles est une source archéologique à lui seul à la vue des lots céramiques qu'il abrite. Chaque département, excepté la Meuse, a livré du grès en abondance plus ou moins variable.

7 La troisième partie de ce mémoire est réservée à l'étude des grès exhumés rue du Tombois à Metz.

8 L'étude d'un site particulier nous semble patente puisqu'il s'inscrit au cœur même de notre réflexion. La justification de ce choix se base sur certains critères incontournables.

De la fouille de la rue du Tombois naît un ensemble clos, c'est-à-dire que les structures mises à jour permettent de déterminer le début et la fin de l'occupation du site grâce à une parfaite stratigraphie. Dans ce contexte, les matériaux exhumés bénéficient d'une datation précise, notamment pour les grès qui font l'objet de notre étude. Il faut souligner l'opportunité de pouvoir étudier un ensemble clos, puisqu'en Lorraine il existe peu de sites pourvus de structures clairement stratifiées.

10 L'étude technique des grès exhumés rue du Tombois repose uniquement sur des observations visuelles : celle-ci comprend une analyse de la pâte, de la cuisson et des glaçures. Ce mémoire propose également une typologie des éléments remarquables observés ainsi qu'une étude morphologique des divers récipients. Les estimations chiffrées sont proposées à titre indicatif; certains tessons n'ayant pu être parfaitement identifiés, ces pourcentages doivent être considérés avec prudence. Cinq types de récipients, disposant de morphologies bien distinctes ont été isolés. Le lot de grès mis au jour comporte des gobelets, des pichets, des cruches, des tasses et des coupelles.

11 Un catalogue raisonné enrichit les analyses en dévoilant les différentes catégories de céramiques exhumées rue du Tombois.

12 Cette étude aurait été incomplète en omettant d'élargir le sujet. Les pistes de recherches proposées font l'objet d'une quatrième et dernière partie.

13 Dans un premier temps, nous avons expliqué pourquoi il serait intéressant de dépasser les limites chronologiques définies pour ce mémoire. Des brides de réflexion ont été émises. Elles méritent sans doute d'être développées et examinées plus précisément. La deuxième piste de recherche s'articule autour de l'origine de cette céramique : peut-on envisager une production locale ou importée? La céramique, en tant que "document d'histoire ", est un témoin de l'histoire sociale, matérielle et économique. Le grès peut être traité au-delà de son étude typochronologique et morphologique. C'est pourquoi l'aspect socio-économique de la commercialisation et de l'utilisation de cette céramique nous semble être une piste de recherche à explorer.

16 Pour répondre aux nombreuses interrogations qui demeurent et éclaircir les zones d'ombres, un travail de synthèse sur les grès lorrains semble s'imposer. Il permettrait d'enrichir et de développer davantage la céramologie en Lorraine. 
INDEX

Index géographique : Lorraine

operation Prospection thématique (PRT)

Index chronologique : Moyen Âge*

Thèmes : céramique médiévale, commerce, coupelle, cruche, gobelet, grès, pichet, pot à cuire, sources archéologiques, sources de l'histoire, sources écrites, sources iconographiques, tasse 